\title{
Nilai Budaya dan Makna Simbolis Seni Tradisional Jepang Daruma, Okinasan, Koi-nobori, dan Nagashi-bina
}

\author{
Reny Wiyatasari \\ Program Studi Sastra Jepang, Fakultas Ilmu Budaya Universitas Diponegoro \\ Email : reny.wiyatasari@gmail.com
}

\begin{abstract}
This article aims to explain the cultural value and symbolic meaning contained in traditional Japan's folk arts (mingei). Of the many traditional folk arts in Japan, only four of them are used as the topic of discussion of this article, namely Daruma, Okinasan Koi-nobori, and Nagashi-bina. All four are interesting to study because they contain cultural values and symbolic meanings that illustrate the cultural concepts of Japanese society, both in character and beliefs that are still held and maintained today. Data collection was carried out through literature and interview methods, and analyzed using qualitative analysis techniques.
\end{abstract}

Keywords : Daruma, Okinasan, Koi-nobori, dan Nagashi-bina

\section{Pendahuluan}

Kebudayaan merupakan sistem tanda atau simbol. Tanda atau simbol yang merepresentasikan kebudayaan ini membentuk sistem makna. Clifford Geertz dalam bukunya Interpretation of Culture (1973) menyebutkan kebudayaan terdiri dari tiga bagian utama : Sistem pengetahuan (sistem kognitif), sistem nilai (sistem evaluatif), dan sistem simbol yang memungkinkan interpretasi. Adapun titik pertemuan antara pengetahuan dan nilai yang dimungkinkan oleh simbol inilah yang dinamakan sistem makna (system of meaning). Melalui makna sebuah simbol dapat menerjemahkan pengetahuan menjadi nilai, dan menerjemahkan seperangkat nilai menjadi suatu sistem pengetahuan.

Nilai-nilai ini dipahami dari simbol-simbol untuk merepresentasikan makna yang terkandung. Tanpa representasi simbol, pengetahuan dan nilai yang terkandung dalam kebudayaan tidak akan bisa dipahami maknanya dan akan tetap menjadi sesuatu yang abstrak. Segala perilaku manusia didasarkan pada lambang yang mengarahkan pada suatu nilai tertentu di masyarakat tertentu dan dipahami oleh masyarakat itu sendiri, contohnya: masyarakat Jawa memiliki nilai yang melambangkan bahwa tangan kanan lebih baik dari tangan kiri. Sedangkan dalam masyarakat Jepang adalah hal yang tabu atau dilarang saat menggunakan sumpit, yakni tidak boleh menancapkannya ke dalam nasi karena hal itu seolah sama dengan memberikan sajen kepada arwah leluhur (osonae).

Sebagai suatu realitas yang terjadi di masyarakat, kebudayaan merupakan produk yang dihasilkan oleh masyarakat. Pada umumnya produk-produk tersebut lahir dan diciptakan sebagai bentuk representasi yang terjadi dalam kehidupan masyarakat pemiliknya. Demikian halnya dalam masyarakat Jepang dikenal berbagai kerajinan tangan atau seni rakyat yang lahir dari kehidupan masyarakat yang tidak hanya mencerminkan warna lokal yang sederhana, namun sekaligus juga mencerminkan karakter masyarakatnya. Dari sekian banyak kerajinan rakyat yang populer di Jepang, dalam tulisan ini hanya akan diangkat empat di antaranya, yaitu : Daruma, Okinasan, Koi-nobori, 
dan nagashibina. Fokus pembahasan tidak untuk menggali nilai estetika, namun lebih pada nilainilai budaya dan makna simbolis yang terkandung dari keempat kerajinan tersebut.

\section{Metode}

Metode yang digunakan pada penelitian ini adalah metode kepustakaan Karena itu, dalam pengumpulan data, penulis melakukan penelaahan terhadap pustaka, seperti buku, literatur, serta catatan yang membahas atau menjelaskan tentang seni kerajinan tradisional Jepang, budaya (tradisional), mitologi masyarakat Jepang. Pengumpulan data dilanjutkan juga dengan n melakukan wawancara kepada informan, yakni orang Jepang yang tinggal di Indonesia untuk mendapatkan informasi yang lebih akurat. Data dianalisis menggunakan teknik analisis kualitatif yang terdiri atas pengumpulan data, reduksi data, penyajian data dan penarikan simpulan (Moleong, 1994). Pembahasan akan dijabarkan secara deskriptif.

\section{Hasil dan Pembahasan}

Sebagai hasil cipta karya dan karsa, berbagai kerajinan tangan yang terdapat di Jepang memiliki sejarah yang panjang sejak ratusan tahun yang lalu. Sebagian besar dari seni kerajinan tradisional tersebut dibawa dari Cina, dan banyak dipengaruhi oleh ajaran Shinto maupun agama Budha.

\subsection{Nilai Budaya pada Boneka Daruma}

Daruma atau dikenal dengan sebutan boneka Daruma merupakan kerajinan tradisional Jepang yang terbuat dari kertas yang di bagian dasarnya diberi pemberat. Daruma adalah terjemahan bahasa Jepang untuk nama Boddhidarma, seorang bijaksana Budha yang membawa bentuk agama Budha ke Cina Selatan dan seorang suci pendiri agama Budha Zen. Boneka Daruma memiliki bentuk bulat berwarna merah yang terdiri atas kepala tanpa lengan dan tubuh dan di sekeliling mata berwarna hitam. Bagi masyarakat Jepang, boneka Daruma diyakini sebagai boneka pembawa keberuntungan dan simbol harapan yang belum terwujud. Gumma-ken adalah salah satu prefektur di Jepang yang terkenal sebagai daerah pembuat boneka Daruma.

Biasanya boneka ini dijual dengan kedua belah mata belum diberi gambar atau dalam keadaan kosong. Mereka yang membeli Daruma biasanya ingin membuat permohonan khusus dengan bantuan para dewa. Maka, sebelum seseorang berkomitmen untuk melakukan suatu usaha, ia akan mendapatkan Daruma dengan kedua mata kosong. Agar harapan atau keinginannya terkabul, ia akan menggambar dengan menghitamkan salah satu sisi mata Daruma dengan spidol atau tinta, sedangkan sisi lainnya dibiarkan begitu saja. Sampai suatu saat ketika usaha atau harapan tersebut terkabul, ia akan menghitamkan sisi mata lainnya. Dengan membiarkan salah satu sisi mata dalam keadaan kosong diharapkan seseorang akan menjadi fokus mengejar harapannya atau tekun berusaha, sehingga akhirnya ia bisa menghitamkan sisi mata lainnya.

Adaya pemberat di bagian dasar boneka ini menjadi salah satu keunikan lainnya dari boneka Daruma. Karena ketika didorong, boneka ini dengan sendirinya bisa berdiri kembali. Daruma jenis ini disebut juga sebagai okiagari koboshi, yang secara literal berarti biksu yang bangun/bangkit dengan mudah. Kalau di Jepang dikenal adanya pepatah "Nana korobi nana yaoki" (tujuh kali jatuh, delapan kali bangkit), maka orang akan mengindektikannya dengan karakter yang dimiliki boneka 
Daruma yang tegar. Karena itu, Daruma juga menyimbolkan semangat pantang menyerah, suatu konsep ketahanan bangsa Jepang yang tergambar melalui semangat "gambaru".

Kata gambaru secara literal berarti bertahan dalam tugas dengan kegigihan sampai selesai atau sama juga dengan semangat pantang menyerah. Sebagai suatu konsep ketahanan bangsa Jepang, semangat gambaru yang sudah mengakar secara mendalam budaya bangsa Jepang dapat dlihat dalam berbagai segi budaya bangsa Jepang, termasuk juga di bidang pendidikan, ekonomi, bisnis, olahraga, dan sebagainya. Fakta menunjukkan bahwa Jepang, meskipun sempat mengalami masamasa kegelapan, kondisi sulit dan kritis akibat berbagai peristiwa dan bencana alam yang dasyat yang banyak menelan begitu banyak korban jiwa, seperti peristiwa bom di Hiroshima dan Nagasaki (1945) dan gempa serta tsunami yang terjadi Tohoku atau Sendai (2011), tetap mampu bertahan, dan gigih berjuang untuk bangkit dari keterpurukan.

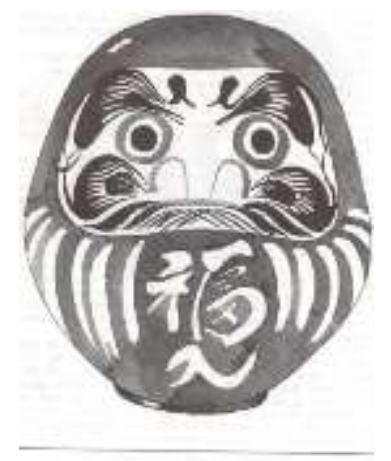

Gambar 2. Daruma

\subsection{Nilai Budaya pada Okinasan}

Sebutan lain dari Okinasan adalah Hachiman yang merupakan nama dewa perang Jepang dalam kepercayaan Shinto. Sama halnya dengan Daruma, Okinasan juga memiliki bentuk seperti boneka yang bagian dasarnya juga diberi pemberat, sehingga apabila didorong akan kembali ke posisi semula. Meskipun ada yang beranggapan bahwa boneka Okinasan merupakan varian dari Daruma, namun sebenarnya secara historis keduanya memiliki sejarah yang berbeda. Okinasan sendiri berasal dari Ishikawa-ken, salah satu prefektur di Okinawa. Nama lengkap yang sebenarnya dari boneka ini adalah Kaga Hachiman Okiagari, namun penduduk setempat lebih suka sebutan yang lebih pendek, yaitu Okinasan. Kata Kaga berasal dari nama salah satu wilayah yang terdapat di Ishikawa-ken yang memiliki sejarah yang tua. Hachiman diambil dari nama dewa dalam kepercayaan Shinto, sedangkan dalam agama Budha, hachiman adalah nama salah satu dewa yang disembah sebagai Budha agung dan pelidung kuil Budha. Kata okiagari adalah kombinasi dari kata oki (dari verba oki-ru 'bangun') dan agari (dari verba agar-u 'naik') yang secara literal mengandung arti bangun atau bangkit. Bagian dasar boneka yang diberi pemberat yang membuatnya akan tetap bangkit sekalipun jatuh atau dijatuhkan berulangkali menjadi pengingat untuk tidak mudah menyerah, coba dan coba lagi.

Sebagai boneka engi (engi berarti : tanda-tanda nasib baik atau nasib jelek), Okinasan dipercaya akan memberi banyak keberuntungan bagi mereka yang memilikinya. Di antaranya, jika menyimpan boneka ini di lemari, maka orang tersebut akan diberkati dan dilimpahi banyak pakaian. Bagi pasangan yang baru menikah, jika menerima boneka ini, dijamin akan dapat membesarkan 
anak-anak yang sehat. Sedangkan bagi orang yang sakit, dengan mendapatkan boneka ini akan dibantu untuk menghilangkan penyakitnya.

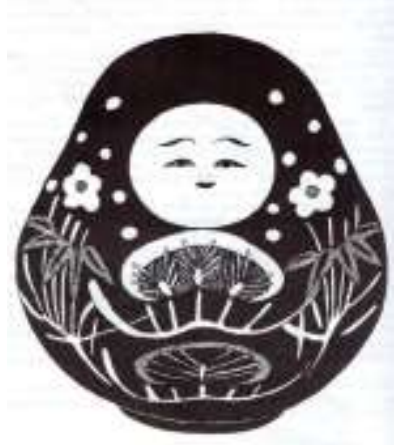

\subsection{Makna Simbolis Koi-nobori}

Gambar 2. Okinasan

Sebutan Koi-nobori terdiri atas dua kata, yaitu koi dan nobori. Koi adalah salah nama salah satu ikan yang juga dikenal di Indonesia sebagai ikan yang sering dipelihara sebagai ikan hias. Sedangkan kata nobori (dari verba noboru) berarti menaiki; memanjat; mendaki (Matsura, 1994). Secara harfiah Koi-nobori bisa diartikan sebagai ikan mas terbang. Ketika perayaan festival hari anak (kodomono-hi) yang dikhususkan untuk anak laki-laki setiap tanggal 5 Mei, panji-panji berbentuk Koi-nobori yang ditegakkan menggunakan tiang tinggi dengan warna cerah yang berkibar di udara menjadi pemandangan yang paling mencolok. Hal demikian bisa disaksikan selama beberapa minggu sebelum dan sesudah berlangsungnya perayaan. Biasanya panji-panji Koi-nobori dipasang di setiap rumah yang memiliki anak laki-laki. Kalau dulu biasanya satu panji Koi-nobori untuk satu anak laki-laki, maka sekarang tanpa memperhitungkan jumlah anak laki-laki yang dimiliki, umumnya setiap rumah memasang dua atau tiga saja.

Ikan Koi adalah jenis ikan yang dihormati di Jepang karena kekuatan yang dimilikinya untuk berjuang melawan arus di hulu sungai. Bahkan dalam salah satu peribahasa Jepang dikenal ungkapan Koi no taki nobori 'Ikan koi mendaki air terjun' (Perlunya perjuangan keras untuk berhasil) yang mengandung nilai budaya kerja keras. Kekuatan dan tekad untuk mengatasi rintangan serta ajaran untuk bekerja keras yang disimbolkan dari karakter ikan ini diyakini sebagai contoh yang sesuai untuk karakter seorang anak laki-laki. Karena itu, masyarakat Jepang yang memiliki anak laki-laki mengibarkan panji Koi-nobori dengan dengan harapan bahwa kelak anak laki-laki mereka akan memiliki karakter seperti halnya karakter yang dimiliki oleh ikan koi.

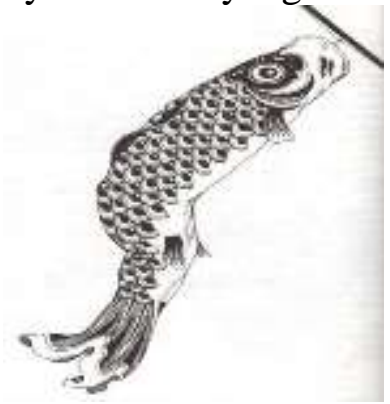

Gambar 3. Koi-nobori 


\subsection{Makna Simbolis Nagashi-bina}

Boneka Nagashi-bina berasal dari Tottori, salah satu prefektur yang ada di pulau Honshu. Kata Nagashi-bina terdiri atas kata nagashi (dari verba nagas-u 'menghayutkan') dan kata bina (dari kata hina 'boneka'). Boneka Okinasan terbuat dari tanah liat dan kertas, dan umumnya dibuat berpasangan. Kimono yang digunakan pada boneka ini biasanya berwarna merah dihiasi dengan hiasan putih sederhana dengan pola titik sederhana yang menyerupai bunga persik. Nagashi-bina terdiri atas dua jenis yang salah satunya terdiri atas satu set berisi 10 pasang boneka. Set lainnya adalah adalah kumpulan yang diilustrasikan dibingkai dalam bentuk alas jerami yang mengapung. Bunga persik yang tergambar di kimono kertas yang menghiasi Nagashi-bina melambangkan kesetiaan dan kebahagiaan dalam pernikahan. Bunga persik sekaligus juga menandakan karateristik kelembutan wanita dan kedamaian.

Biasanya boneka higashi-bina akan dipajang di altar saat merayakan hari anak perempuan atau yang disebut Hina-matsuri (festival boneka) setiap tanggal 3 Maret. Perayaan ini menjadi kesempatan bagi keluarga di Jepang yang memiliki anak perempuan memohon agar anak perempuannya tumbuh dengan sehat. Berbagai department store menampilkan display hina-ningyoo (boneka hina) tujuah hingga delapan tingkat.

Saat perayaan Hina-matsuri, masyarakat Jepang, khususnya masyarakat di Tottori-ken mempunyai kebiasaan membeli dua set boneka higashi-bina. Satu untuk disimpan satu lagi untuk dihanyutkan dengan tujuan agar mereka terlindungi sepanjang tahun yang akan datang. Boneka yang dipajang di tahun lalu dibawa ke tepi laut atau sungai untuk dihanyutkan karena ada keyakinan bila tidak disingkirkan, maka pernikahan seseorang akan tertunda. Ketika boneka-boneka yang dihanyutkan tersebut hilang dari pandangan, maka diyakini kesialan, nasib buruk, ketidakbahagiaanakan hilang dibawa pergi bersama dengan tokoh-tokoh yang ada di boneka. Sebaliknya harapan akan terhidar dari kemalangan akan datang ke dalam kehidupan mereka.

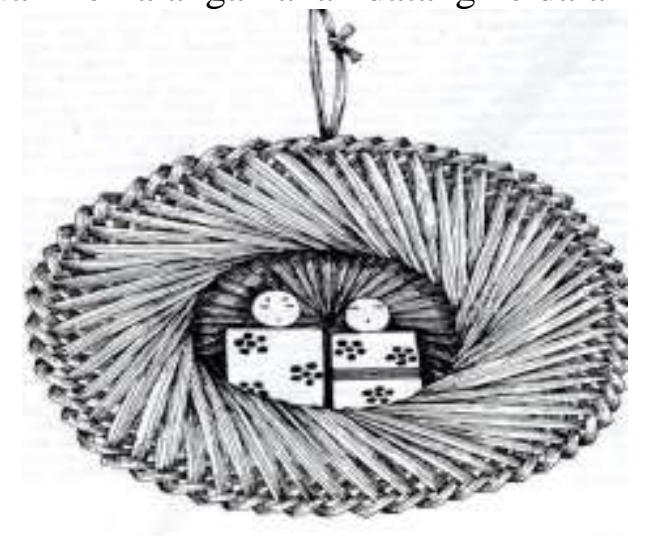

Gambar 4. Nagashi-bina

\section{Simpulan}

Dari keempat seni kerajinan tradisional Jepang yang sudah diulas di atas diketahui adanya nilai-nilai budaya dan makna simbolis yang secara garis besar adalah sebagai berikut :

1. Nilai budaya tidak mudah menyerah/pantang menyerah yang disimbolkan dari karakter boneka Daruma dan Okinasan. Betapapun dijatuhkan akan tetap bangkit sekaligus menjadi ciri khas 
karakter yang dimiliki oleh masyarakat Jepang dengan semboyan yang familiar diucapkan yaitu : Gambatte (dari kata gambaru).

2. Semangat untuk berusaha mengejar harapan dan cita-cita serta budaya bekerja keras merupakan nilai yang terkandung dari Daruma, khususnya warna hitam pada matanya serta karakter yang dimiliki ikan koi yang digambarkan melalui ungkapan Koi no taki nobori. Ini sekaligus menggambarkan karakter bangsa Jepang sebagai bangsa yang dikenal sebagai pekerja keras.

3. Karakter Ikan Koi yang berenang menentang arus juga mengandung makna simbolis keberanian dan kekuatan dalam mengatasi masalah diharapkan akan dimiliki oleh anak laki-laki di Jepang.

4. Makna simbolis keberuntungan dan nasib baik, dijauhkan kemalangan dan ketidakbahagaan digambarkan dari seni tradisional Jepang Okinasan dan Nagashi-bina. Jika memiliki atau menyimpan Okinasan diyakini akan memberikan banyak berkah, maka sebaliknya, membuang boneka Nagashi-bina dengan cara dihayutkan dipercaya akan membawa kesialan.

\section{Daftar Pustaka}

Ashkenazi, Michael. 2003. Handbook Of Japanese Mythology. California. ABC CLIO, Inc

Geertz, Clifford. 1973. Interpretation of Culture. New York. Basic Books.

Giles, Amaury Saint. 1983. MINGEI. Japan's Enduring Folk Arts. Rutland, Vermont and Tokyo, Japan. Charles E. Tuttle Company

Kouichi, Ueno. 2005. 日本絵とき事典 1. Illustrated. A Look Into Japan.

JTB パブリッツグ. Tokyo.

Matsura, Kenji.1994. Kamus Jepang-Indonesia. Jakarta. PT. Gramedia Pustaka Utama Moleong, Lexy J. 1994. Metode Penelitian Kualitatif. Bandung. Remaja Rosdakarya.

Sasaki, Mizue. 1995. View of Today's Japan. ALC. Tokyo

Unduhan Website :

http://web-japan.org/ https://www.presentationzen.com/presentationzen/2011/03/fall-down-seven-times-get-up-eight-thepower-of-japanese-resilience.html 